Article

\title{
Walking in Balance: Native American Recovery Programmes
}

\section{Suzanne Owen ${ }^{1,2}$}

1 Theology and Religious Studies, University of Chester, Parkgate Campus, Chester CH1 4BJ, UK;

E-Mail: suzanne.owen@chester.ac.uk; Tel.: +44-0-1244-511-031

2 Theology and Religious Studies, Leeds Trinity University, Brownberrie Lane, Leeds LS18 5HD, UK

External Editors: Chris Cook and Wendy Dossett

Received: 25 August 2014; in revised form: 16 September 2014 / Accepted: 28 September 2014 /

Published: 20 October 2014

\begin{abstract}
This article reviews Native American ritual practices, frameworks and key concepts employed by several substance abuse treatments centres in the U.S. and Canada. It also examines the way Alcoholics Anonymous' Twelve Step programme has been modified to attract and serve the needs of Native Americans and First Nations and its potential impact on the ritual practices. Native concepts of wellbeing are highlighted and linked to the idea of living in "balance".
\end{abstract}

Keywords: native American; aboriginal Canadian; twelve step; medicine wheel; community; elders; balance; wellbeing

\section{Introduction}

The majority of Native American-led addiction recovery programmes employ Native American rituals yet are based on the Twelve Step programme of Alcoholics Anonymous. This leads to questions of why Twelve Step is considered both an ideal model for Native Americans to use and at the same time a poor fit unless altered to incorporate Native American cultural tools for healing and concepts of wellbeing that include a focus on community, elements that are thought to make such treatment programmes distinctively "Native American" [1,2]. I had previously researched the use of pan-Native American ritual practices among the Mi'kmaq of Canada for overcoming trauma, which also highlighted the importance of community for individual healing [3]. It is of little surprise that the types of practices employed in alcohol recovery programmes are also ones that are considered pan-Native American. As a consequence, treatment programmes may be fuelling their popular use more widely. 
In this article, I will highlight the Native American practices employed by several substance abuse treatment centres in the U.S. and Canada and the way the Twelve Step programme has been modified to attract and serve the needs of Native Americans and First Nations. ${ }^{1}$ I will end with an examination of a common Native American concept of wellbeing, which is connected to the idea of living in "balance", emerging from discourses within the context of recovery from addiction.

First, a prevalent argument stated in much of the literature on Native American addiction recovery is that alcoholism among Native Americans is due to the impact of colonialism. At Poundmaker's Lodge in Alberta according to Waldram, Herring and Young: "The loss of cultural identity is considered to be a root cause of an individual's substance-abuse problems." ([4], p. 254). These cultural arguments are frequently stated by clients and staff at treatment centres, as Manitowabi and Shawande discovered: "In research interviews conducted, many made reference to colonial intrusions such as residential schools, Christianity, and social and economic displacement leading to a disruption in Anishinabe wellbeing." ([5], p. 452, using a variant spelling of Anishinaabe). Likewise, anthropologist Erica Prussing observed that on the Northern Cheyenne Reservation in Montana, "many who use [the Twelve Step rhetoric] also explicitly address colonialism as a cause of drinking" ([6], p. 3). Clinical psychologist Joseph Gone also discussed the impact and legacy of colonisation on Native peoples more generally in his 2011 article "The Red Road to Wellness" ([7], p. 187). However, Waldram, Herring and Young say there is a danger in trying to show that the loss of traditional methods of coping and a sense of powerlessness led to a reliance on alcohol as this emphasises the "Aboriginal as victim" ([4], p. 267). The choice to employ traditional ceremonies and frameworks may then be part of a wider decolonizing effort to overcome cultural traumas and reclaim Native American traditions and identities.

\section{Native American Ritual Practices}

Between 1978 and 1985, Joan Weibel-Orlando reviewed over fifty Native American substance abuse programmes and found that the most effective ones, summarised by psychologist Laurence French, were "generated by natives themselves", "had charismatic role models", had involved individuals in a group both as client and healer, and "saw themselves as social entities" providing an alternative to drinking cultures ([1], p. 82; [8]). The treatment centres discussed in this article have these components and equip individuals with tools and frameworks for continued use after completing the programmes, hence the reason why some of the clients in turn become healers or teachers. This appears to have been a positive by-product from the beginning. According to French: "An early success using a variation of this native treatment model was established at the Nebraska Penal Complex in the mid-1970s as a reaction to the incarceration of American Indian Movement warriors." ([1], p. 92). Sweat lodges and other services were provided by the Native American Spiritual and Cultural Awareness (NASCA) association. "Those who were initiated to these traditional customs while incarcerated at the Nebraska Penal Complex later became traditional healers among their people

1 In this article, I will use the term Native or Native American broadly when not referring to a specific group to include all indigenous peoples in North America, although in Canada the more common terms are First Nations or Aboriginal Canadian. Also, in North American contexts, substance "abuse" (rather than "misuse" or "harmful use") is the more common terminology. 
at the tribal level and within the urban Indian centers." ([1], pp. 93-94). This would suggest that many of the contemporary Native healers are themselves in recovery.

Journalist Christopher Ringwald also thought the use of Native American rituals and frameworks in substance abuse programmes began in the 1970s ([2], p. 87), which is also the period that saw a resurgence of interest in Native American practices among supporters of the American Indian Movement and other counter-cultural groups, such as those objecting to the Vietnam War. Black Elk Speaks, the story of the Lakota holy man originally published in 1932, was reissued in 1972 and became a "bible" for Native Americans wanting to reconnect with their "roots" ([9], p. xv), even if they were not Lakota. Also in 1972, leaders of the American Indian Movement turned to the Lakota on Pine Ridge reservation for spiritual guidance from holy men such as Black Elk's nephew, Frank Fools Crow ([10], p. 36). Thus, Lakota cultural practices were shared and popularised among many tribal nations (and beyond) and provided a model for pan-Native American ritual practices employed in recovery programmes. It must be remembered that this was before the 1978 American Indian Religious Freedom Act. As French noted: "The Sioux [Lakota] traditions of the sacred pipe, purification sweat, vision quest, and the Sun Dance, all once outlawed and their practitioners severely punished, have emerged as treatment and training processes for native healers among both the Plains Indians and pan-Indians" ([1], p. 92).

Christopher Ringwald also referred to the use of talking circles, medicine wheels and sweat lodges as part of treatment methods ([2], p. 82). In a talking circle, a person can speak when he or she is holding a designated object (often an eagle feather, or a carved stick on its own) that is passed around the circle. Usually there is no requirement to speak and one can pass the object on to the next person. It is a method that is quite wide-spread, also within non-Native groups, and may simply be referred to as a "sharing circle".

The theme of the circle continues with the 'medicine wheel', mainly derived from the Plains Indians, although the four directions, which is what it represents at its most basic level, is found throughout the Americas and elsewhere. In more contemporary Native American usages, the four quadrants symbolise different areas of life, such as infancy, youth, maturity and old age, and other aspects and elements associated with those. It can also include above, below and centre to make seven "directions". It can take any number of concepts, as long as they come in groups of four or seven, which makes it eminently adaptable across different cultures each with their own language and symbols. One administrator told Gone: "The medicine wheel takes in everything that we know, have known, and can accommodate what is to be known." ([7], p. 194). As an example, Gone says that at the Healing Lodge in Canada where he conducted his research the medicine wheel's four quadrants were linked to four aspects of human experience, the physical, mental, emotional, and spiritual. The therapeutic project, then, "was to promote client awareness of all four aspects of the self and to facilitate the pursuit of balance among these facets of experience through healthier lifestyle choices" ([7], p. 194). As it provides a structure for looking at different areas of life, the medicine wheel is easily adapted to substance abuse treatment programmes. "As a consequence, even the western approaches were structured within an overtly Aboriginal frame of reference." ([7], p. 195), especially the notion of the "self" as a project to be developed in the four areas of life represented by the four quadrants of the medicine wheel.

Finally, the sweat lodge ceremony, as it is commonly known (following a Plains Indian model), involves bringing in heated stones and pouring water on them to create steam. There are usually four "rounds", which, like the medicine wheel, often represent four ages of life, providing the focus of 
prayers, but otherwise is mainly a purification ceremony that can occur at the start of other ceremonies, such as the sun dance. Many centres include the sweat lodge ceremony as a part of the treatment programme and it has gained more attention in scholarship than many other Native-derived ritual practices. Schiff and Moore discuss the efficacy of the sweat lodge ceremony for Native American wellbeing in their article, where they note that: "Along with a rise in interest in natural and Indigenous healing practices, and a revival of traditional Indigenous ceremonies, the sweat lodge has been increasingly used by both Indigenous and non-Indigenous peoples as a means of healing in multiple dimensions of body, mind, emotion, and spirit." ([11], p. 48), referring here to the four aspects of human experience noted by Gone above, stated frequently in Native American healing discourses.

\section{Native American-Led Recovery Programmes: Examples}

In his book The Soul of Recovery, Ringwald provides a number of case studies of recovery centres in the United States that employ pan-Native American practices, usually alongside Twelve Step. One such place is "Indian Rehab" in Phoenix, Arizona, which was started in 1972 by two Native Americans who "sobered up and sought to help others" ([2], p. 90). The centre uses the three common ritual practices already described: the talking circle, medicine wheel and sweat lodge. According to Ringwald, members of fifty-four different tribes had attended Indian Rehab during a three month period in 1997 and said facilitators had allowed for cultural variations, but had described the talking circle as "pan-Indian". However, some tribes did not allow women to hold an eagle feather used to pass around the circle ([2], p. 91). One counsellor told Ringwald that: "The use of these methods does not harken back to ancient times so much as it represents modern adaptation. Powwows arose among tribes elsewhere in the country, sweat lodges were imported from the Lakota, and talking circles are a relatively new thing" ([2], p. 92). Many of these have become standardised in treatment programmes so that staff from different backgrounds can offer them and clients can find similar cultural features at other centres. These also feature in many inter-tribal gatherings, such as powwows. However, there is room for more tribal-specific content and Ringwald gives an example of an Alcoholics Anonymous group in Minnesota where residents "learned to drum and chanted Ojibwe songs from a tribal elder" ([2], p. 84), as well as participate in sweat lodge ceremonies. "Rather than being strictly tribal or sectarian, the rites and rituals are portable and adaptable, say practitioners. 'When I go to a Sioux sweat lodge, they ask me to call to my own Ojibwe ancestors"”, one said to Ringwald ([2], p. 89).

In Canada, similar features are present at treatment centres there. Clinical psychologist Joseph Gone (a member of the Gros Ventre Nation) carried out an empirical case study of a Native-led programme at the "Healing Lodge" on an Algonquian First Nations reserve combining western and indigenous approaches that were integrated using the medicine wheel. His study focussed on the outpatient counselling service funded by the Aboriginal Healing Foundation, set up to heal those affected by the residential school system ([7], pp. 188-89). Of the clients he interviewed, only two had direct experience of residential schooling while the others had relatives who experienced it ([7], p. 189). The programme included lectures on residential schooling and an associated fieldtrip to a former residential school ([7], p. 191).

Clients told Gone that they learned about ceremonies such as sun dances and sweat lodges and made craft items such as dream catchers ([7], p. 191). One client said: "This is where I started my 
healing journey. And this is where I practiced my Native culture. I go to sweat [lodge ceremonie]s, I go to fasting [camp]s, I go to powwows, and participate. It's a good feeling when you're starting to find your identity. To have that sense of belonging... and to have that identity in the purpose of life." ([7], p. 192). The main Aboriginal approaches employed at the Healing Lodge included "prayer and 'smudging' (i.e., purifying oneself by burning sacred plants), talking circles, tobacco offerings, pipe ceremonies, sweat lodge rituals, fasting camps, and various other blessing rites (e.g., ritual renewal of the colored cloths that marked the directional entrances to the Lodge)" ([7], p. 192). The prayers would include Christian ones as well as Native ones for giving thanks. As for the lectures, Gone noted that "topics included a combination of both Aboriginal cultural orientation (e.g., seven sacred directions (i.e., a medicine wheel, community values, residential schools) and mainstream 'life skills' instruction (e.g., alcohol and drugs, self-esteem, communication skills)" ([7], p. 191). Additionally, the Healing Lodge made an effort to serve locals: "program counsellors were involved in sponsoring cultural activities for the community (e.g., a pipe ceremony in honor of residential school survivors)" ([7], p. 193). Ceremonial leaders were also prominent:

[The Healing] Lodge employed a full-time "traditional counselor" whose responsibilities included the formulation and facilitation of additional cultural activities within standard treatment regimens. For example, the traditional counselor conducted a sweat lodge ceremony every Thursday afternoon for clients. Finally, nine of the staff at the Lodgeincluding the majority of the counseling program staff-identified as "pipe carriers", which means that they had obtained the right and responsibility to ritually care for and pray with a sacred pipe. As a result, client encounters with Aboriginal culture and traditioneven though full participation was strictly optional-were routine. Some clients had never participated in these activities prior to their time in the program ([7], p. 193).

As pipe-carriers, they would be recognised by the wider community for serving that community.

The two examples provided by Ringwald and Gone above show the prevalence of pan-Native American practices such as the talking circle, medicine wheel and sweat lodge ceremonies, although one treatment centre is in the southwest USA and the other is in northern Canada. The final example of a Native-led centre I will discuss is Poundmaker's Lodge, an Aboriginal alcohol treatment centre outside Edmonton in Alberta, Canada, attended by Herb Nabigon and discussed by Waldram, Herring and Young. In his autobiographical book, The Hollow Tree: Fighting Addiction with Traditional Native Healing, Nabigon, who is Anishinaabe, described it as based on the Twelve-Step recovery programme "combined with Native American healing traditions" ([12], pp. 30-31). Like the Healing Lodge, Poundmaker's emphasises cultural education in treating substance abuse and incorporates a number of pan-Native American ceremonies. Waldram, Herring and Young say that "all patients are required to attend sweetgrass ceremonies morning and evening..." ([4], p. 254). From my experience, this would involve "smudging" where the smoke from the burning sweetgrass is either fanned out, using a feather, in the direction of each individual or each person scoops the smoke over themselves as the sweetgrass is taken around the circle. Leaders might say that it transforms negative energy into positive; certainly participants usually feel uplifted by it. In the circle, they allow "time to pray in their own way and in their own language, and time is made available for them to talk, in turn, about what may be on their mind" ([4], pp. 254-55). There is no overt pressure to talk and ceremonies such as the 
sweat lodge are offered but not mandatory ([4], p. 255). Nabigon also mentioned being taken to a sweat lodge there ([12], p. 31). The Elders taught him "the Hub", described as a Cree conception of the self, interwoven with the medicine wheel, that includes "the four stages of life: infancy, youth, adulthood and the Elder years" ([12], pp. 43, 116), which is of course not uniquely Cree.

A significant dimension of Native-led recovery programmes are the roles played by Elders and the community as these aid the social integration of clients. Herb Nabigon defines an Elder as "an Aboriginal person who is close to the Creator and the Spirit World". They often conduct healing ceremonies, but, more often, an Elder is regarded as "an individual who has good balance" ([12], p. 115); here I follow Nabigon's example in capitalising the word Elder to show that it signifies a particular status), which would come from years of observation and experience of the world. At Poundmaker's Lodge in Alberta, "Elders, who may or may not be healers, are invariably involved in the programming." ([4], p. 255). One Cree Elder said to Waldram that "he sought to help patients reconnect with whatever Aboriginal culture they were from." ([4], p. 255). In The Hollow Tree that one of the Elders at Poundmaker's Lodge suggested to Nabigon that he do a four-day fast to begin his "sacred journey". "Fasting and ancient teachings from the Elders helped me set aside the alcohol and pick up and carry my sacred pipe.” ([12], pp. 33-34).

The importance of community cannot be overstated as personal healing is always in relation to others. This is illustrated by the sweat lodge ceremony, which can have four rounds for praying to children, the young people, the ill and the elderly. When Lakota and many others enter the lodge, they say "all my relations", acknowledging that healing requires co-operation from others (not all of whom are human). Native-led programmes often make "community" central to their philosophy, such as ones run by White Bison, a successful Native American charitable organisation founded in 1988 by President Don Coyhis (Mohican Nation), based in Colorado Springs. In their statement, they say they believe that "change comes from within the individual, the family and the community", the "solution resides within each community" and "Interconnectedness - it takes everyone to heal the community" [13]. This type of philosophy is put into practice at the Healing Lodge on an Algonquian First Nations reserve in Canada. Gone was told that "program staff also hosted cultural activities for the community, including powwow dances, pipe ceremonies, and an annual fasting camp. Although clients were always encouraged to participate, staff strove to engage community members at large in these activities as part of a collective healing process", adding that confidentiality about being on the programme was not an issue for clients as it was not easy to keep it a secret anyway in such a close-knit community ([7], p. 192).

\section{Native Adaptations to Twelve Step}

As Waldram, Herring and Young have noted, "the most successful treatment programs seem to be based on traditional healing approaches, Alcoholics Anonymous, or a combination of both" ([4], p. 269). This is reflected in White Bison, which facilitates the Wellbriety Movement for addition recovery and provides the Warrior Down support programme based on Twelve Step and the medicine wheel to help veterans and people returning from prisons. In their Wellbriety Treatment Center Certification Criteria for certifying programmes using their materials, it includes: "Have relationship and ready access to at least one Native American Elder (ideally a male and a female) for advice and to conduct ceremonies" and "Ensure that Native traditional healing practices are incorporated into treatment programs 
(smudging, pipe ceremony, sweat lodge, naming ceremony, healing ceremony, as appropriate for the individuals cultural needs)" [14]. The institute provides a curriculum, DVDs and other resources to enable centres to provide a full programme.

Often, Twelve Step statements are translated into different Native languages, substituting words like "God" with "Creator", which is a more common address for deity among Native Americans, or "Great Spirit", "but the basic model remains intact" ([1], p. 90; [2], p. 101; [4], p. 255). At the Healing Lodge, an administrator referred to Twelve Step as a "spiritual" programme, which is likely the reason it is attractive to those adapting it for Native American treatment programmes. In Joseph Gone's observation, Twelve Step is not the only western-derived model he found there; he also observed influences "from popular psychology and alternative or New Age medicine: inner child explorations, guided imagery, meditation and visualization, anger discharge, acupuncture, neurolinguistic programming, genogram mapping, reiki, energy work, and cosmo therapy" ([7], p. 192).

Looking at Native American adaptations of the Twelve Step programme in more detail, it is usual to find an alteration to both the format and wording. Regarding the format, Laurence French states that "sessions are usually circular and incorporate elements of the medicine wheel, purification sweat, and sacred pipe as healing devices. Within this therapeutic milieu, the abuse of alcoholism [sic] and other substances is viewed as a broken-hoop of broken-circle issue" ([1], p. 89). French describes the standard version of Alcoholics Anonymous as "rooted in the protestant ethic", while the "values of harmony ethos", emphasising group cooperation and respect for nature, are attributed to Native American cultures ([1], pp. 4, 89). As an example, with French uncritically mirroring the essentialisms found in the treatment programmes themselves, he contrasts the standard "Critical attitude" with the Native American "Uncritical attitude"; "Competition" with "Cooperation"; "Ownership" with "Sharing"; "Honor self" with "Honor elders"; "Verbalism" with "Silence" and "Individualism" with "Tribal values" ([1], p. 89). The wording of the Steps has been changed to reflect these values. Where Step 11 in the standard AA version states: "Seek through prayer and meditation to improve our conscious contact with God, as we understand him, praying only for knowledge of His will for us and the power to carry that out", in the Native American version, according to French, it states (my emphasis, to show alteration): "Seek through prayer and meditation to improve our conscious contact with the Equality and Brotherhood of all Mother Earth's children and the Great Balancing Harmony of the Total Universe." ([1], p. 90). Balance and harmony are often stated values, discussed below.

Ringwald noted in a programme he surveyed that: "Purification is added to the need for prayer and meditation, and several references to family and brothers and sisters are included" ([2], p. 101). At a centre in Minnesota, women and men are at the drum when traditionally women sing behind the men at the drum ([2], p. 102). This can be observed at powwows, where Plains Indian-derived protocols for drumming and other aspects, such as the wearing of eagle feathers, are modelled (see [15]).

\section{Controversies}

Integrations of Twelve Step and similar models into Native American cultures has led to some concerns by scholars and members of Native communities. Joseph Gone noted the impact within a treatment centre in his study: "Although incorporations of indigenous culture marked the [Healing] Lodge program as distinctly Aboriginal in character, the subtle but profound influence of western 
'therapy culture' was centrally evident in healing practices as well' ([7], p. 187). Not only are these Native-derived practices absorbing the language and values of "therapy culture", he also observed that counsellors "selfconsciously engaged in the incorporation of Aboriginal approaches and practices into their more conventional treatment efforts, effectively institutionalizing several of these" ([7], p. 193). He does not indicate the impact of this on healing practices outside treatment programmes, but this is likely to be considerable if some of those who complete the programmes go on to become healers in the wider community. This is an area that needs further study.

Erica Prussing found that the use of Cheyenne spiritual practices in treatment programmes does spark debate among the Northern Cheyenne in her study. Many women she interviewed wove "elements of 12 Step approaches with efforts to learn and revitalize Cheyenne ritual practices" ([6], p. 3). She says these efforts have gained both support and criticism in the local community. Using Twelve Step itself is problematic for a few because the vocabulary and concepts alienates some people ([6], p. 7). As noted by French above, Prussing implies that Alcoholics Anonymous' Protestant values are at odds with Cheyenne values:

A.A.'s distinctly Anglo-American flavor is evident in how Twelve Step concepts and practices are firmly grounded within broader Protestant traditions, including an emphasis on self-control, themes of conversion and surrender, and the central role of personal testimony, and through being voluntary and individual (rather than coerced by hierarchical authority).... Arguably, Twelve Step approaches also reflect a broader contemporary American cultural tendency to define spirituality in psychological terms... ([6], p. 16).

Thus, there is a psychologising of Native American cultural practices and frameworks, which is notable in the use of the medicine wheel discussed above.

Likewise, Joseph Gone discusses "healing discourse", personal pain and trauma, including the legacy of colonialism, and says part of the treatment is to "verbalise" this pain. "More specifically, cathartic self-expression was expected to inaugurate a process of searching reflexivity and selfexamination that could sustain positive and ongoing transformations of the self." ([7], p. 195). Since the "self" becomes a "therapeutic project", “"working on' oneself, one's 'issues', or one's life was emblematic of the healing journey that signified a lifelong process of introspection, transformation, and fulfillment" ([7], p. 196); "healing discourse" is evident throughout Herb Nabigon's The Hollow Tree). Confirming Laurence French's view that Native Americans value silence over verbalism, Gone heard that at the Healing Lodge it was often challenging to get clients to talk, and "the difficulties associated with eliciting therapeutic talk from clients was attributed in part to enduring community norms that devalued or proscribed such verbal self-expression" ([7], p. 196). Thus, "in contrast to the self-consciously selected and rhetorically effective celebration of recognizable Aboriginal symbols and practices at the Lodge, healing discourse among staff and clients was also seen to depend heavily (but implicitly) on more familiar aspects of mainstream "therapy culture" ([7], p. 197). In other words, Native American practices have been subverted to suit the therapy agenda derived from non-Native sources such as Twelve Step. Treatment programmes, in effect, are engaged in a universalising commodification and appropriation of Native American cultural practices.

One way to overcome the tendency toward reticence in these contexts is to incorporate traditional storytelling and songs, somewhat overlooked in many of these sources. During an Aboriginal Day 
event in western Newfoundland, Mi'kmaq included storytelling and songs within different ritual contexts, such as the sunset ceremony, and one elder told a traditional story about Kluskap, a Mi'kmaq cultural hero, during the talking circle. Clients quoted in Joseph Gone's article refer to their "story" ([7], pp. 191, 195). Bridging the practice of storytelling with narrating the personal journey through addiction and recovery is one way of bridging 12 Step and Native American traditions.

One challenge faced by treatment centres regards the employment of traditional healers and Elders. According to a prevalent traditional view, their services cannot be "bought", but people may donate what they can or give some token of appreciation after a healing or ceremony (see [10]). Ringwald explains that: "Within Indian treatment circles, there are some tensions regarding the proper role of traditional healing and spirituality, paying for such services, and the potential for misuse.” ([2], p. 99). There is a problem that many "medicine men" do not want to be paid for their services if they hold to traditional values ([2], p. 100). It is possible to give monetary or other material gifts afterward in a show of appreciation to elders and healers. There is a subtle difference. Paying for services brings an expectation that a healing or teaching will be performed, taking away the power from the healer or Elder to not perform, if the situation makes it difficult (such as attitudes of organisers or participants).

Another tension Ringwald highlights is that "Some Native Americans worry that their spiritual practices will be distorted even among their own people due to ignorance", because many clients are unfamiliar with their culture's traditions ([2], p. 101). They would not easily recognise how a cultural practice has been modified; however, all such practices have undergone continuous change and are adapted to each circumstance. "Will practicing ceremonies outside their original context or locale lead to misuse or even mutation?" asks Ringwald ([2], p. 102). In answer, I would say there are only "mutations" if one accepts that there are "pure" practices, but that is not possible. However, the debate over perceived misuse is more complex and connected to issues of appropriation more widely (see [10]). For those undergoing treatment, there are more pragmatic concerns for "whatever works".

\section{Balance and Wellbeing}

In studies of the discourse around Native American recovery programmes, the prevalence of "therapy speak" has been noted by Gone and Prussing. One concept articulated frequently among Native Americans and First Nations in such discourse is that of "balance". This is apparent in in Georges Sioui's "Forward" to Herb Nabigon's, The Hollow Tree, which is peppered with conceptions of balance as well as a view of what it is to be "unbalanced":

This book is destined to shine as an example of the power of our Elders to use their spiritual gifts to turn their people away from unbalanced life ways and self-destructive feelings such as hate, resentment, inferiority, and jealousy towards a life guided by kindness, honesty, courage, and humility ([16], pp. ix-x).

In the twenty-five years of friendship that we share, I have seen my "Neechee" Herb Nabigon walk away from the doom of alcohol, hurt, and despair to the place of high respectability, personal balance, and collective hope... ([16], p. xi). 
Sioui implies that a balanced life includes kindness, honesty, etc., while an unbalanced one includes hate, resentment, etc., and that Nabigon had, through his recovery from alcohol abuse, turned away from an unbalanced life toward one that is balanced.

Nabigon himself also uses the term frequently: "Our society can balance itself if more emphasis is placed upon spirituality in our everyday lives, for without spirituality we will perish. We will perish if we continue to over-emphasize the rational and logical sides of life, forgetting the need for balance." ([12], p. xvii). The tool he uses "on a daily basis" is a Cree version of the medicine wheel "to maintain balance in my life", which is represented by the eagle feather ([12], p. 43). An aspect of the Plains Indian medicine wheel teaching picked up by those in recovery is the "red road". The wheel has within it a cross representing the two axes, the black and the red. The black "road" is thought to represent difficulties and imbalance, at least in therapy discourses (it also has an association with power), while the red represents growth and balance. As Herb Nabigon learned at Poundmaker's Lodge: "The people who walk the red road attempt to balance their lives between goodness and fear" ([12], p. 47). Fasting also helped and, referring to his first fast, he said it "was my first attempt to balance my life; to balance my life like Nature balances itself through the four changing seasons" ([12], p. 77).

The idea of balance is often linked to conceptions of wellbeing, stemming from different linguistic terms to mean the "good life" or similar. According to Manitowabi and Shawande, "the Anishinabek of Manitoulin Island have no single concept of 'health' or 'wellbeing'. The closest term is 'mnaamodzawin', meaning a 'good, holistic way of life'.” ([5], p. 443; [17], p. 44). In Hallowell's highly regarded study of Ojibwe (or Anishinaabe) ontology, he relates the conception of "wellbeing" to having "balance" involving reciprocal relationships with others, including non-human persons (animals, stones, etc.). "One of the prime values of Ojibwe culture is exemplified by the great stress laid upon sharing what one has with others. A balance, a sense of proportion must be maintained in all interpersonal relations and activities." ([7], pp. 45-46).

When Manitowabi and Shawande asked their research participants, "What does traditional medicine mean to you?", and they all made some reference to "holism". In an example they give, "balance" is prominent, as well as "therapy discourse": "it is more less holistic, it's the whole four elements of the self, emotional, mental, physical, spiritual, I guess it's the balance of the self, and if one is affected then there's no balance, you need to take a look at that and it takes time, it's a lifelong healing process." ([5], p. 449). This quote also suggests that the self is a project needing development, highlighted by Joseph Gone ([7], pp. 194-96). Manitowabi and Shawande do add that "balance" was another of the recurring key words expressed by participants ([5], p. 452): "Interviewees spoke about balance as key to wellbeing and healing, and the need to nurture one's body spirit... Clients stated that healing is tied to balance which suggests that imbalance is linked to a state of unhealthiness" ([5], pp. 453-54). In summary, they state that: "In essence, wellbeing means a balanced way of life. If an imbalance occurs one must return to a state of equilibrium leading to a long healthy life." ([5], p. 454).

Sociologist Geoffrey Mercer also claims that indigenous concepts of health are inseparable from family, community and the world, represented as a circle ([18], p. 144). He quotes Joan Feather, who says:

The Native concept of health...is said to be holistic because it integrates and gives equal emphasis to the physical, spiritual, mental and emotional aspects of the person. The circle 
is used to represent the inseparability of the individual, family, community and world...The circle (or wheel) embodies the notion of health as harmony or balance in all aspects of one's life ([18], p. 144; [19]).

This is also noted by Glen McCabe when describing the "medicine wheel" or circle as a tool in counselling representing "balance" and "harmony" ([20], p. 145). "Harmony", like "holism" and "balance", also occurs frequently in discourse about health and wellbeing. In another example, Long, David and Fox say "for Native people, health implies being in harmony with all of creation" ([21], p. 241).

Many of these statements explicitly refer to the need for harmonious relations with non-human persons, including "nature", as well as human persons. This proposes a view that wellbeing is not personal, but collective, because what one does individually affects the wellbeing of others.

\section{Conclusions}

Alcoholic Anonymous' Twelve Step is as widely used in Native American-led programmes as elsewhere. While the programme leaders recognise that there are potential cultural barriers that make adopting Twelve Step wholesale alienating for many Native Americans, the model remains intact. Despite the additions of Native American cultural values such as "community" to the wording, it still revolves around clients verbalising their traumas and fears and focussing on the self as a project. However, as indicated in the section above on controversies, many of these barriers can be overcome, and have been, through the use of storytelling as an aid to verbalizing fears and traumas. Rather than focussing on each client as a disconnected individual, Native-led treatments centres also make an effort to focus on the "self in community", with its history, culture and social relations. More research is needed on the role of storytelling for improving treatment outcomes.

Programmes employing Twelve Step have also incorporated the same types of Native American ritual practices, mainly the talking circle, medicine wheel and sweat lodge. The medicine wheel in particular has provided a "Native American" framework for organising the content and focus of programmes, most commonly the four stages of life (childhood, youth, maturity and old age) and the four dimensions of self (physical, mental, emotional and spiritual). These practices have become "pan-Native American" and are found in recovery programmes throughout North America. The question remains about whether Native American ritual practices are now predominantly sustained through the involvement of those in recovery and if this skews the practices toward healing and pan-Native American models. The link between treatment programmes and the revitalisation of Native American cultural practices is an intriguing one and is a significant area for further research In my previous research on the relationship between cultural alienation brought on by residential schooling, among other factors, and the revitalization of the sweat lodge ceremony, a few Mi'kmaq referred to their years of "sobriety" and a history substance abuse [3]. Another area for future research that arises from this study is the discourse on colonization and the use of Native American practices and frameworks as a decolonization practice.

In some cases, Native-led treatment programmes see substance abuse as a symptom of the loss of their culture and pride. As part of the cultural educational programme, such as at the Healing Lodge in Alberta, these aspects are addressed. While there is some critique of that emphasis, there is little doubt 
that cultural education supports treatment of Native Americans in recovery. One client said to Joseph Gone, "I used to be ashamed for being an Indian....I'm proud to be a Native now." ([7], p. 193).

\section{Conflicts of Interest}

The author declares no conflict of interest.

\section{References}

1. Laurence Armand French. Addictions and Native Americans. West Port: Praeger, 2000.

2. Christopher D Ringwald. The Soul of Recovery: Uncovering the Spiritual Dimension in the Treatment of Addictions. Cary: Oxford University Press, 2002.

3. Suzanne Owen. "Prayer with Pain: Ceremonial Suffering among the Mi'kmaq." In Indigenous Bodies: Reviewing, Relocating, Reclaiming. Edited by Jacqueline Fear-Segal and Rebecca Tillett. Albany: State University of New York Press, 2013, pp. 129-43.

4. James Burgess Waldram, D. Ann Herring, and T. Kue Young. Aboriginal Health in Canada: Historical, Cultural, and Epidemiological Perspectives. Toronto: University of Toronto Press, 1995.

5. Darrel Manitowabi, and Marjory Shawande. "The Meaning of Anishinabe Healing and Wellbeing on Manitoulin Island." Pimatisiwin: A Journal of Aboriginal and Indigenous Community Health 9 (2011): 441-58.

6. Erica Prussing. White Man's Water: The Politics of Sobriety in a Native American Community. Tucson: University of Arizona Press, 2011.

7. Joseph P. Gone. "The Red Road to Wellness: Cultural Reclamation in a Native First Nations Community Treatment Center." American Journal of Community Psychology 47 (2011): 187-202.

8. Joan Weibel-Orlando. "Hooked on healing: Anthropologists, alcohol and intervention." Human Organization 48 (1989): 148-55.

9. Vine Deloria, Jr. "Forward." In Black Elk Speaks: Being the Story of a Holy Man of the Oglala Sioux. Edited by John G. Neihardt. Lincoln: University of Nebraska Press, 1979, pp. xi-xiv.

10. Suzanne Owen. The Appropriation of Native American Spirituality. London and New York: Continuum, 2008.

11. Jeannette Wagemakers Schiff, and Kerrie Moore. "The impact of the sweat lodge ceremony on dimensions of well-being." American Indian and Alaska Native Mental Health Research: The Journal of the National Center 13 (2006): 48-69.

12. Herb Nabigon. The Hollow Tree: Fighting Addiction with Traditional Native Healing. Montreal and Kingston: McGill-Queens University Press, 2006.

13. White Bison. "White Bison's Philosophy." Available online: http://www.whitebison.org/whitebison/white-bison-philosophy.php (accessed on 30 July 2014).

14. White Bison Wellbriety Training Institute. Wellbriety Treatment Center Certification Criteria. Colorado Springs: White Bison, 2013. Available online: http://www.whitebison.org/documents/ CertifiedTreatmentCriteria_2013web.pdf (accessed on 25 July 2014).

15. Suzanne Owen. "Production of Sacred Space in the Mi'kmaq Powwow." DISKUS, August 2010. Available online: http://basr.ac.uk/diskus_old/diskus11/owen.htm (accessed on 14 October 2014). 
16. Georges Sioui. "Forward." In The Hollow Tree: Fighting Addiction with Traditional Native Healing. Edited by Herb Nabigon. Montreal and Kingston: McGill-Queens University Press, 2006, pp. ix-xii.

17. Alfred Irving Hallowell. "Ojibwa ontology, behaviour, and world view." In Readings in Indigenous Religions. Edited by Graham Harvey. London and New York: Continuum, 2002, pp. $17-49$.

18. Geoffrey Mercer. "Aboriginal Peoples: Health and Healing." In Aboriginal People and Other Canadians: Shaping New Relationships. Edited by Martin Thornton and Roy Todd. Ottawa: University of Ottawa Press, 2001, pp. 131-59.

19. Joan Feather. Social Health in Northern Saskatchewan: Discussion Papers for Working Group on Social Health. Saskatoon: University of Saskatchewan Northern Medical Services, 1991.

20. Glen McCabe. "Mind, body, emotions and spirit: Reaching to the ancestors for healing." Counselling Psychology Quarterly 21 (2008): 143-52.

21. David Alan Long, and Terry Fox. "Circles of Healing: Illness, Healing, and Health among Aboriginal People in Canada." In Visions of the Heart: Canadian Aboriginal Issues. Edited by David Allan Long and Olive Patricia Dickason. Toronto: Harcourt Brace, 1996, pp. 239-69.

(C) 2014 by the author; licensee MDPI, Basel, Switzerland. This article is an open access article distributed under the terms and conditions of the Creative Commons Attribution license (http://creativecommons.org/licenses/by/4.0/). 